\title{
unr, a cellular cytoplasmic RNA-binding protein with five cold-shock domains, is required for internal initiation of translation of human rhinovirus RNA
}

\author{
Sarah L. Hunt, ${ }^{1}$ Justin J. Hsuan, $^{2}$ Nicholas Totty, ${ }^{2}$ and Richard J. Jackson ${ }^{1,4}$ \\ ${ }^{1}$ Department of Biochemistry, University of Cambridge, Old Addenbrooke's Site, Cambridge, CB2 1GA, UK; ${ }^{2}$ Ludwig \\ Institute for Cancer Research, Middlesex Hospital, University College Branch, London, W1P 8BT, UK
}

Initiation of translation of the animal picornavirus RNAs occurs via a mechanism of direct ribosome entry, which requires a segment of the 5' UTR of the RNA, known as the internal ribosome entry site (IRES). In addition, translation of the enterovirus and rhinovirus (HRV) subgroups requires cellular trans-acting factors that are absent from, or limiting in rabbit reticulocytes, but are more abundant in HeLa cell extracts. It has been shown previously that HeLa cells contain two separable activities, each of which independently stimulates HRV IRES-dependent translation when used to supplement reticulocyte lysate; one of these activities was identified as polypyrimidine tract-binding protein (PTB). Here, the purification of the second activity is achieved by use of an RNA-affinity column based on the HRV 5' UTR. It comprises two components: a $38-\mathrm{kD}$ protein (p38), which is a novel member of the GH-WD repeat protein family and has no intrinsic RNA-binding activity; and a 96- to $97-\mathrm{kD}$ protein doublet, which was identified as unr, an RNA-binding protein with five cold-shock domains. Coimmunoprecipitation with antibodies against either protein shows that the two proteins interact with each other, and thus p38 is named unrip (unr-interacting protein). Recombinant unr acts synergistically with recombinant PTB to stimulate translation dependent on the rhinovirus IRES. In contrast, unr did not significantly augment the PTB-dependent stimulation of poliovirus IRES activity.

[Key Words: Human rhinovirus; poliovirus; translation initiation; IRES; RNA-binding proteins]

Received October 15, 1998; revised version accepted December 28, 1998.

A number of viral mRNAs and a few cellular mRNAs are translated by an unusual mechanism of direct internal ribosome entry, in contrast to the conventional scanning mechanism of initiation site selection. The animal picornavirus RNAs constitute the prototype of this unconventional mechanism (Jang et al. 1988; Pelletier and Sonenberg 1988) and still remain the best understood example (Jackson and Kaminski 1995). Internal initiation of translation of picornavirus RNAs requires a substantial segment (about 450 nucleotides long) of the viral 5' UTR, but the extreme 5'-proximal part of the 5' UTR is not strictly necessary. The minimal cis-acting RNA element is generally known as the internal ribosome entry site (IRES). On the basis of conservation of primary sequence and predicted secondary structure, the picornavirus IRESes (apart from that of hepatitis A virus) can be divided into two main groups: (1) the enterovirus and rhinovirus IRESes; and (2) the cardiovirus and aphthovirus IRESes (for review, see Jackson and Kaminski 1995).

${ }^{4}$ Corresponding author.

E-MAIL rij@mole.bio.cam.ac.uk; FAX (44) 1223-766002.
With the exception of the cap-binding initiation factor eIF4E, internal initiation of translation of picornavirus RNAs seems to require all the canonical initiation factors required for the conventional scanning mechanism (Pestova et al. 1996a,b; Borman et al. 1997; Ohlmann et al. 1997), but it may also need additional trans-acting factors. Here again, the different picornavirus species show differences that parallel the differences in IRES structure. Cardiovirus and aphthovirus RNAs are translated very efficiently in rabbit reticulocyte lysates. In contrast, enterovirus IRESes, such as those of poliovirus or echovirus-25, are rather inefficient in reticulocyte lysates, and rhinovirus IRESes very inefficient unless the assay is supplemented with HeLa cell extracts (Brown and Ehrenfeld 1979; Dorner et al. 1984; Borman et al. 1993, 1995; Bailly et al. 1996).

These observations suggest that the restriction of enterovirus and rhinovirus IRES activity in reticulocyte lysates could be exploited as a functional assay to purify those factors that are necessary for IRES activity but that are either completely absent from reticulocyte lysates or are much less abundant than in HeLa cell extracts. Early 
attempts with poliovirus RNA met with little success, as the activity was lost after only limited purification had been achieved (Svitkin et al. 1988; Jackson 1989). Therefore, we switched to the human rhinovirus (HRV) IRES, as this IRES is even less active in reticulocyte lysates, resulting in a better signal to background ratio (Borman et al. 1993). We anticipated that the same transacting factors would be required for both HRV and poliovirus IRESes, given the close phylogenetic relationship between the viruses and the strong similarity in the structures of their IRESes. We have shown previously that HeLa cells have two activities that stimulate HRV IRES activity, and we identified one as polypyrimidine tract-binding protein (PTB), a protein previously considered to be a constitutive pre-mRNA splicing factor but now thought to be a negative regulator of alternative splicing (Patton et al. 1991; Lin and Patton 1995). In accordance with the expectations stated above, PTB was found to stimulate the activity not only of the HRV IRES, but also the poliovirus IRES (Hunt and Jackson 1999).

Here, we report the purification and characterization of the second stimulatory activity, previously known as the B-type activity (Borman et al. 1993), and compare its influence on HRV and poliovirus IRES function.

\section{Results}

\section{Purification of the B-type activity}

The activity of the HRV IRES requires one or more protein factors that are much more abundant in HeLa cells than in rabbit reticulocytes, as supported by the observation that IRES-dependent translation is very inefficient in reticulocyte lysates but can be rescued by addition of HeLa cell extracts (Borman et al. 1993). Fractionation of HeLa cell extracts by ion-exchange chromatography shows that there are two separable stimulatory activities, previously named A- and B-type activities; each individually can enhance HRV IRES activity but their stimulatory effect when tested in combination is at least additive and, more often, synergistic (Hunt and Jackson 1999). In a previous publication, we reported the purification of the A-type activity and its identification as PTB and also described the partial purification of the B-type activity, which copurified with a $\sim 97 \mathrm{kD}$ protein that can be cross-linked to the HRV IRES by UV irradiation (Hunt and Jackson 1999).

The purification of the B-type activity was completed by use of an HRV 5' UTR RNA-affinity column, which proved exceptionally selective in binding only a limited subset of proteins at $200 \mathrm{~mm} \mathrm{KCl} \mathrm{(Fig.} \mathrm{1A).} \mathrm{Among} \mathrm{the}$ proteins that bound and were eluted by the salt gradient, there was a doublet estimated as $96-97 \mathrm{kD}$ peaking in fraction 27 and also a protein of $38 \mathrm{kD}$ that precisely coeluted in apparent stoichiometric relative yield with the doublet (Fig. 1A). UV cross-linking reactions with a ${ }^{32}$ P-labeled HRV 5' UTR probe showed that the crosslinkable $\sim 97-\mathrm{kD}$ protein in the column load was recovered in a single peak centered on fraction 27 , but no cross-linking of the $38-\mathrm{kD}$ protein (p38) was seen (Fig. 1B). For consistency with previous publications (Borman et al. 1993; Hunt and Jackson 1999), we will continue to designate the doublet as p97.

The column fractions were added to reticulocyte lysate translation assays to test for their ability to stimulate IRES-dependent translation of the standard (uncapped) dicistronic XLJHRV 10-611 mRNA, which consists of an upstream cistron coding for Xenopus laevis cyclin B2 and the complete HRV-2 5' UTR (except for the first 9 nucleotides) in the intercistronic space fused directly to a slightly truncated form of the influenza virus NS1 reading frame, referred to as NS' (Borman et al. 1993; Hunt and Jackson 1999). A small peak of stimulatory activity was found in fractions 26-28 (data not shown). After each fraction had been concentrated 10fold, a repeat assay confirmed the recovery of activity in fractions 26-30 (Fig. 1C), with the only difference that the peak appeared to be in fraction 26 rather than 27 , which is probably because the assay of fraction 27 may have been oversaturated and subject to some nonspecific inhibition by the excess protein. No such inhibition was seen when fraction 27 was assayed prior to concentration (Fig. 1D). We estimate that the concentration of p97 in the assays shown in Figure 1C ranged from about $2 \mu \mathrm{g} /$ $\mathrm{ml}$ for fraction 29 up to $>10 \mu \mathrm{g} / \mathrm{ml}$, or $100 \mathrm{nM}$, for fraction 27. In comparison, the dicistronic mRNA concentration $(10 \mu \mathrm{g} / \mathrm{ml})$ used throughout this work corresponds to $10 \mathrm{~nm}$.

We have shown previously that there is at least additive stimulation of HRV IRES-dependent translation when partially purified B-type activity is assayed together with either purified HeLa A-type activity or recombinant PTB (Hunt and Jackson 1999). Figure 1D shows that this same property is retained by HeLa cell B-type activity that has been purified to homogeneity: The increment in NS' yield caused by the addition of both factors together is greater than the sum of the increments brought about by each individually, that is, their combined effect is synergistic. It should be noted that the concentration of recombinant PTB used in this experiment $(10 \mu \mathrm{g} / \mathrm{ml})$ has been shown previously to be saturating (Hunt and Jackson 1999): Half-maximal stimulation was seen at $\sim 1 \mu \mathrm{g} / \mathrm{ml}$ and maximal stimulation at $2.5-5 \mu \mathrm{g} / \mathrm{ml}$. In view of the importance of this issue, during the course of this work, we routinely verified that $10 \mu \mathrm{g} / \mathrm{ml}$ of recombinant protein did indeed effect the maximum stimulation of IRES activity that could be achieved by PTB alone.

\section{p38 is a novel member of the GH-WD repeat protein family}

Purified p38 and p97 were digested with proteases and the fractionated peptides subjected to amino acid sequencing. For p38, sequences spanning $>40 \%$ of the whole protein were obtained. There were no matches to any known protein, only to a number of ESTs, but this situation allowed nonredundant primers to be used to PCR amplify from a HeLa cell cDNA library a fragment 
$\mathbf{A}$ $200 \mathrm{mM} \mathrm{KCl}$ flow-through and wash

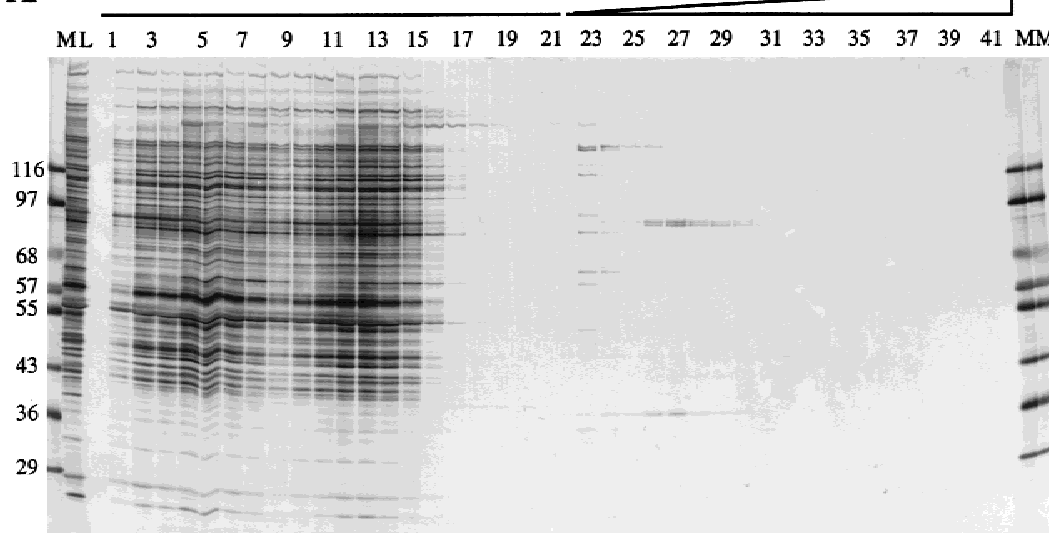

B

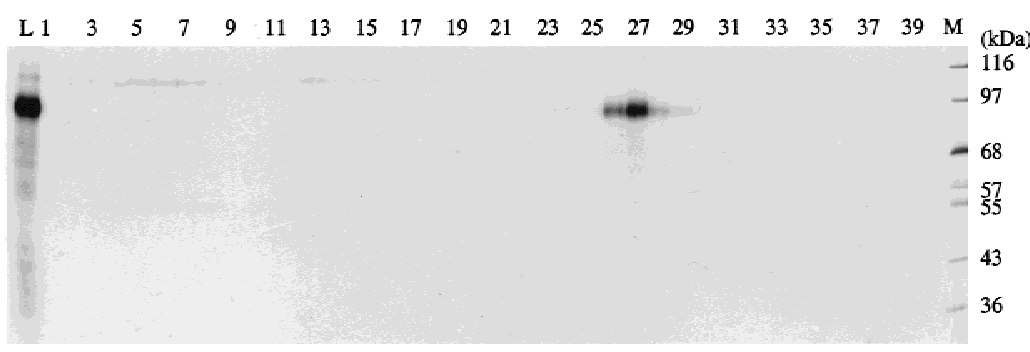

C

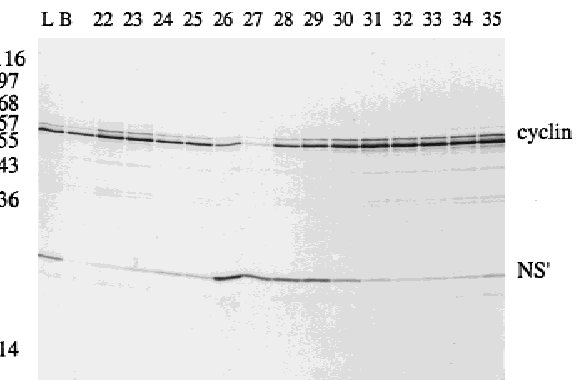

D

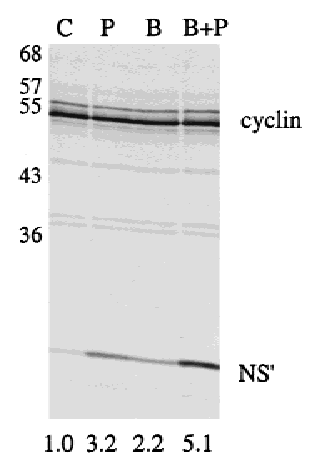

Figure 1. HRV-2 5' UTR RNA-affinity purification of HeLa cell B-type activity. HeLa cell B-type activity was partially purified by ion-exchange chromatography (see Materials and Methods) and then applied to an HRV 5' UTR affinity column. Fractions 1-8 are flowthrough fractions, which were recycled over the matrix once and recollected as flowthrough fractions 9-16. Fractions 17-22 represent the $200 \mathrm{~mm} \mathrm{KCl}$ wash, and fractions 2341 , the $200-1000 \mathrm{~mm} \mathrm{KCl}$ gradient. (A) Silverstained SDS $/ 12.5 \%$ polyacrylamide gel of the column load (L) and fractions 1-41. (M) Protein molecular weight markers, of sizes indicated in $\mathrm{kD}$ in the left hand margin. (B) UV cross-linking of the column load (L) and fractions 1-40 to ${ }^{32} \mathrm{P}$-labeled HRV 5' UTR RNA. A fluorogram of the ${ }^{32} \mathrm{P}$-labeled proteins, analyzed by SDS $/ 15 \%$ polyacrylamide gel electrophoresis, is shown. UV cross-linking assays were carried out as described previously (Hunt and Jackson 1999) with $0.1 \mathrm{mg} / \mathrm{ml}$ heparin as a nonspecific competitor and a probe transcribed from pJHRV10-605, which consists of the complete HRV 5' UTR (except for the first 9 nucleotides) plus the initiation codon, but without coding sequences. The reactions were carried out in the presence of $1 \mathrm{mg} / \mathrm{ml} \mathrm{BSA}_{\text {; }}$ the absence of BSA (or $1 \mu$ of reticulocyte lysate) the p97 signal was seen in precisely the same fractions but was weaker, presumably because of the low protein concentration. $(C)$ Translation assays of the uncapped dicistronic XLJHRV10-611 mRNA in reticulocyte lysate, supplemented with $17 \%$ (vol/vol) column load (L) or fractions 22-35, which had been concentrated 10-fold by use of Microcon-10 microconcentrator units. (B) Negative control reaction supplemented with $17 \%$ ( $\mathrm{vol} / \mathrm{vol})$ H500 buffer. An autoradiograph of the translation products analyzed by SDS $/ 20 \%$ polyacrylamide gel electrophoresis is shown. The upstream cistron translation product (cyclin) and downstream cistron translation product

$\left(\mathrm{NS}^{\prime}\right)$ are indicated. $(D)$ Purified B-type activity acts synergistically with recombinant PTB to stimulate HRV IRES-dependent translation. Uncapped dicistronic XLJHRV10-611 mRNA was translated in reticulocyte lysate in the presence of either $10 \mu \mathrm{g} / \mathrm{ml} \mathrm{recom}$ binant GST-PTB (P), 16\% (vol/vol) fraction 27 of the RNA affinity column from Fig. 1, prior to it being concentrated (B), or a combination of both $(\mathrm{B}+\mathrm{P})$. (C) Negative control reaction with no added factors. The yield of radiolabeled NS' in each assay was determined by quantitative densitometry and is given below each lane, expressed relative to the yield in the buffer control assay, which was assigned a value of 1.0.

of the p38 cDNA, which was used to screen the library for a longer, putatively full-length, p38 cDNA (see Materials and Methods). The deduced amino acid sequence shows that $\mathrm{p} 38$ is a novel member of the GH-WD repeat protein family (Fig. 2). It has six putative GH-WD repeats, of which five have all three residues of the AspHis-Ser/Thr structural triad first identified in G $\beta$ (Sondek et al. 1996), whereas the sixth has only the Asp residue, which corresponds to the only residue absolutely conserved among the GH-WD repeats of G $\beta$. However, molecular modeling of the three-dimensional structure of $\mathrm{p} 38$ suggests the existence of a seventh, noncanonical repeat that would allow p38 to adopt a seven- bladed $\beta$-propellor structure similar to that of $G \beta(N$. Srinivasan and T.L. Blundell, pers. comm.). At the amino acid sequence level, p38 shows the greatest resemblance (24.8\% residues identical plus $31.6 \%$ similar) to the 36 $\mathrm{kD}$ subunit of mammalian translation initiation factor eIF3 and its yeast equivalent, which appear to play a critical role in holding the whole multisubunit eIF3 complex together (Naranda et al. 1997).

\section{Identification of p97 as unr}

For the partial sequencing of p97, no attempt was made to separate the two bands of the doublet (Fig. 1A), which 


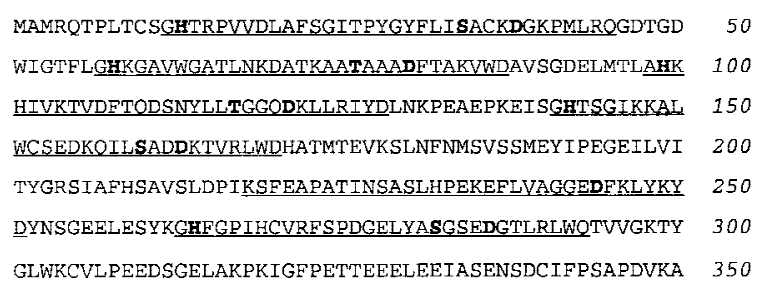

Figure 2. The deduced amino acid sequence of p38. Putative GH-WD motifs are underlined, and the conserved residues of the Asp-His-Ser/Thr structural triad identified by Sondek et al. (1996) in G $\beta$ are shown in bold. The complete nucleotide sequence of the longest p38 cDNA is deposited in the EMBL/ GenBank database (accession no. AJ 010025) and includes a putatively complete $3^{\prime}$ UTR of 495 nucleotides and a 147-nucleotide $5^{\prime}$ UTR.

were taken as one protein. Sequences of peptides totaling 159 amino acid residues were obtained, more than ample to identify p97 as unr (which takes its name from the fact that it is encoded by a gene located only a very short distance upstream of $\underline{\mathrm{N}}$-rias; Jeffers et al. 1990; Nicolaiew et al. 1991). Subsequently unr was identified as a member of the cold-shock family of single-stranded nucleic acid-binding proteins (Doniger et al. 1992; Boussadia et al. 1993), which are now considered to be more RNA than DNA specific (Graumann and Marahiel 1998). However, unr is atypical in two respects (Graumann and Marahiel 1998): It has multiple cold-shock domains, in fact five, and all five domains share a sequence signature not found in any other protein of the family (Fig. 3). X-ray crystallography and the NMR solution structure of the Bacillus subtilis major cold-shock protein, supported by site-directed mutagenesis, suggested that the nucleic
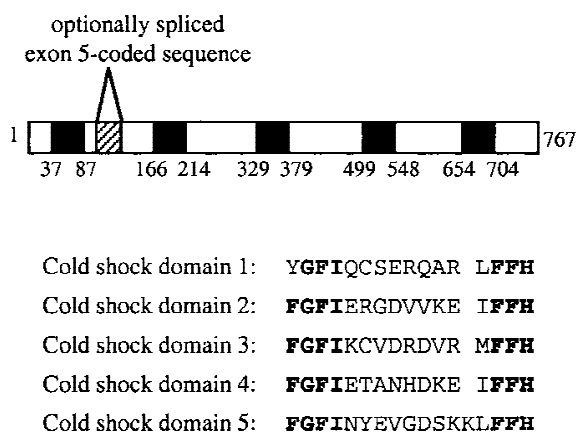

Consensus: $\quad(\mathbf{F} / \mathbf{Y}) \mathbf{G F I}\{9 / 10$ amino acids $\} \mathbf{F F H}$

Figure 3. A schematic representation of unr. Cold-shock domains are represented by black boxes, and the number of the first and last amino acid residues of each is indicated (numbering corresponds to the isoform lacking exon 5). The optionally spliced exon 5 -encoded sequences are shown as a hatched box. The sequences of the conserved core of the five unr cold-shock domains which, by analogy with the cold-shock domain protein CspB (Schindelin et al. 1993; Schnuchel et al. 1993), are proposed to form the RNA-binding surface, are aligned below. Those residues that occur in four or more of the sequences are in bold. acid-binding surface consists of a tetrapeptide F/YGFI motif and, separated by a 9-amino-acid spacer, a more carboxy-terminal tripeptide FVH motif, both of them almost absolutely conserved among proteins of this family (Schindelin et al. 1993; Schnuchel et al. 1993; Schröder et al. 1995). What is unusual about the cold-shock domains of unr is that, in all five of them, the canonical FVH is replaced by FFH (and, in addition, the most carboxy-terminal domain has a 10-amino-acid spacer).

Although the function of unr is not known, it is an essential protein: The homozygous mouse knockout is embryonic lethal (Boussadia et al. 1997). It is largely cytoplasmic in location and partly polyribosome associated (Jacquemin-Sablon et al. 1994). There are two known isoforms, differing by inclusion or exclusion of the optionally spliced exon 5 (Fig. 3; Boussadia et al. 1993). The peptide sequences obtained for our HeLa cell p97 did not include any match to exon 5 , but as only $\sim 20 \%$ of the protein was sequenced, this result does not rule out that our preparation includes the larger isoform. It is formally possible that the doublet noted in Figure 1A represents the two isoforms, but we consider this possibility unlikely because the difference in apparent size we observe seems smaller than would be expected for a 31-aminoacid insert and is actually smaller than the difference in size between recombinant versions of the two isoforms. Moreover, it is reported that at the RNA level, the smaller isoform is about 10 -fold more abundant than the larger in most tissues and cell types examined (Boussadia et al. 1993), and thus it seems more likely that our p97 is the smaller isoform lacking exon 5 sequences and that the doublet (Fig. 1A) may arise from incomplete posttranslational modification.

\section{Activity of recombinant unr and p38 in promoting translation dependent on the HRV IRES}

Clones corresponding to both isoforms of unr were isolated from a HeLa cell cDNA library (see Materials and Methods). These sequences and the p38 cDNA were subcloned for overexpression in E. coli with a carboxy-terminal hexahistidine fusion, and the proteins were also expressed as GST-fusion proteins, which were subsequently treated with thrombin to release the recombinant protein. For each protein, we found no difference between the properties of the histidine-tagged and GSTtagged versions when added to reticulocyte lysate translation assays programmed with the dicistronic XLJHRV 10-611 mRNA. For consistency, all further work described here was solely with the histidine-tagged versions. Figure 4 shows that the separate addition of either isoform of unr had only a very small effect (a maximum of $40 \%$ stimulation over the buffer control) on HRV IRES-dependent translation. In other experiments, a somewhat greater stimulation has been seen, but never more than about $80 \%$ (see Fig. 6A, below). However, if a saturating concentration of histidine-tagged PTB was added, the combined effect of recombinant PTB and unr was a synergistic stimulation of IRES-dependent translation (Fig. 4A), which was dependent on the dose of unr, 

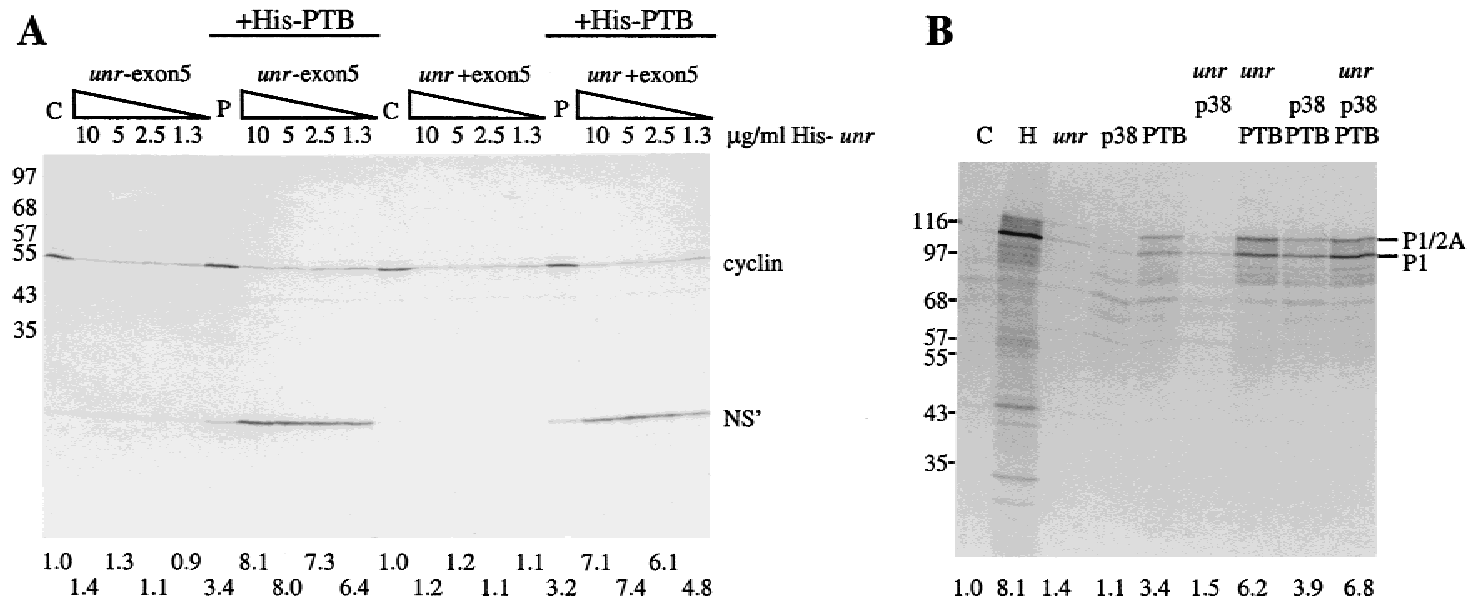

Figure 4. Recombinant unr acts synergistically with PTB to stimulate HRV IRES-dependent translation. $(A)$ Uncapped dicistronic XLJHRV10-611 mRNA was translated in reticulocyte lysate supplemented with recombinant His-unr, either lacking, or containing, the exon 5-encoded sequences (-exon5 and +exon5, respectively), at concentrations of 10, 5, 2.5, or $1.3 \mu \mathrm{g} / \mathrm{ml}$, either separately, or in the presence of $10 \mu \mathrm{g} / \mathrm{ml}$ recombinant His-PTB. Control reactions without the addition of factors (C), or with the addition of $10 \mu \mathrm{g} / \mathrm{ml}$ His-PTB only $(\mathrm{P})$, were also carried out. An autoradiograph of the translation products, analyzed by SDS $/ 20 \%$ polyacrylamide gel electrophoresis, is shown. (B) The effect of recombinant unr, p38, and PTB on translation of HRV-2 genomic RNA. The truncated genomic HRV-2 transcript, HRV-2/NdeI, was translated in reticulocyte lysate supplemented with either $5 \mu \mathrm{g} / \mathrm{ml}$ recombinant His-unr (-exon 5), $20 \mu \mathrm{g} / \mathrm{ml}$ recombinant His-p38, or $10 \mu \mathrm{g} / \mathrm{ml}$ recombinant His-PTB, each separately, or in pairwise combinations, or all three together, as indicated above each lane. A negative control reaction was carried out without the addition of factors $(\mathrm{C})$, and a positive control was supplemented with $20 \%$ (vol/vol) HeLa cell HS S100 extract (H). The yield of radiolabeled NS' in each assay of $A$ and the combined yield of P1-2A and P1 (plus any material of size intermediate between P1 and P1-2A) in $B$ was determined by quantitative densitometry and is given below each lane expressed relative to the yield in the buffer control assay, which was assigned a value of 1.0.

with maximal stimulation achieved by $2.5-5 \mu \mathrm{g} / \mathrm{ml} \mathrm{re}-$ combinant protein. Over several repeat assays with different preparations of recombinant proteins, the smaller of the two isoforms was consistently the more active (Fig. 4A), and so all further work described here was carried out with this isoform lacking exon 5 .

In addition to the stimulatory effect on translation of the downstream IRES-dependent NS' cistron, unr quite strongly inhibited translation of the upstream cyclin cistron of the uncapped dicistronic mRNA in these experiments (Fig. 4A). However, if the RNA is a capped version of the same transcript, unr has no effect on the yield of the upstream cistron product, yet still acts synergistically with PTB to stimulate IRES-dependent translation (see Fig. 6, below, cf. A and C).

We have shown previously that the apparent factor requirement of a picornavirus IRES may be influenced by the nature of the downstream reporter cistron. Under particular circumstances, encephalomyocarditis virus (EMCV) IRES-dependent translation may be switched from being PTB-independent, if the reporter is the viral coding sequence, to being highly PTB-dependent, if a heterologous coding sequence is used (Kaminski and Jackson 1998). To allay fears that the results of Figure 4A are only applicable to the laboratory-constructed dicistronic mRNA, we tested the ability of recombinant unr to promote internal initiation of translation of a truncated version of the rhinovirus genomic RNA, generated by transcription of full-length rhinovirus-2 cDNA (pHRV-2), which had been linearized previously in the P2 coding region. The translation product of this RNA undergoes autocatalyzed cleavage of the 2A moiety from the carboxy-terminal end (Fig. 4B). The yield of P1 plus P1-2A was stimulated slightly by the addition of $5 \mu \mathrm{g} / \mathrm{ml}$ recombinant unr, and more strongly by a saturating concentration of recombinant His-tagged PTB $(10 \mu \mathrm{g} / \mathrm{ml})$, as reported previously (Hunt and Jackson 1999). When tested together, the stimulatory effect of these two components was more than additive (Fig. 4B), just as was observed with the dicistronic mRNA.

In contrast, recombinant p38 had no consistent and significant effect on the yield of HRV P1 and P1-2A, whether added separately, together with recombinant unr or recombinant $\mathrm{PTB}$, or with a combination of both these proteins (Fig. 4B). A similar lack of any significant effect of p38 was seen with the dicistronic mRNA template (see Fig. 6C, below).

\section{The effect of unr/B-type activity on translation directed by the poliovirus IRES}

As explained in the introductory section, the close phylogenetic relationship and strong structural similarity between the poliovirus and HRV IRES led us to expect that the two would require the same set of trans-acting factors. However, when we first tested this proposition using partially purified HeLa cell B-type activity, we found some surprises. As is shown in Figure 5A, addition of B-type activity to an assay of uncapped dicistronic mRNA with the poliovirus IRES did not increase the yield of the downstream cistron product either on its own, or in a system supplemented with recombinant 
Figure 5. The effect of HeLa cell B-type activity on poliovirus type 1 (Mahoney) IRES-dependent translation. (A) Uncapped dicistronic XLJHRV10-611 and XLPV1747 mRNAs were translated in reticulocyte lysate supplemented with either $20 \%$ (vol/vol) partially purified HeLa cell B-type activity, fractionated from HeLa cell cytoplasmic HS S100 extract on heparin-Sepharose and then DEAE-Sepharose (B), $10 \mu \mathrm{g} / \mathrm{ml}$ recombinant His-PTB (P), or a combination of both $(\mathrm{B}+\mathrm{P})$. Negative control reactions were carried out with no addition of factors $(\mathrm{C})$ and positive control reactions with the addition of $20 \%$ (vol/ vol) HeLa cell HS S100 extract (H). An au-
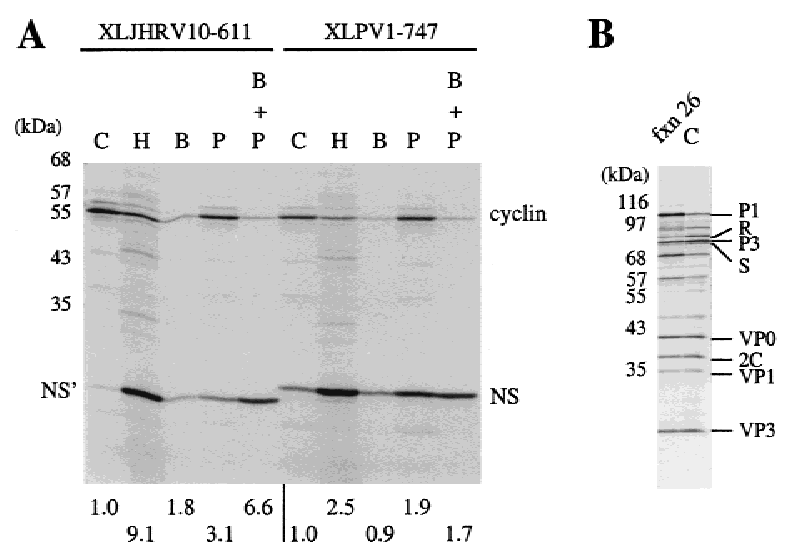

toradiograph of the translation products, analyzed by SDS/20\% polyacrylamide gel electrophoresis, is shown. The difference in size of the IRES-dependent cistron products is because NS' in XLJHRV10-611 is a slightly truncated form of the NS-coding sequence fused directly to the viral initiation codon (Borman and Jackson 1992; Hunt and Jackson 1999), whereas the IRES-dependent cistron in XLPV1-747 is the full-length NS-coding sequence fused to the viral initiation site via a short linker (Hunt and Jackson 1999). (B) Poliovirion RNA (at $10 \mu \mathrm{g} / \mathrm{ml}$ ) was translated in reticulocyte lysate in an assay supplemented with $10 \%$ (vol/vol) fraction $26 \mathrm{from}$ the RNA-affinity column shown in Fig. 1 (after having been concentrated 10-fold). (C) Negative control reaction with no additional factors. The positions of the main polyprotein processing products (P1, P3, VP0, 2C, VP1, and VP3) are indicated at the right, as are the aberrant products (R and S) which arise from initiation events in the P3-coding region (Dorner et al. 1984). (C) Translation assays were carried out as in $A$, except that the mRNA was T7-1/NdeI. The translation product, $\mathrm{P} 1{ }^{\prime}$, is the P1 capsid precursor portion of the poliovirus polyprotein, slightly truncated at the carboxy-terminal end. The yield of radiolabeled NS' or NS in each assay of $A$, and the yield of $\mathrm{P}^{\prime}$ in each assay of $C$ was determined by quantitative densitometry and is given below each lane, expressed relative to the yield in the corresponding buffer control assay, which was assigned a value of 1.0.

PTB, although in the parallel assay of XLJHRV 10-611 mRNA the expected small response to B-type activity on its own and the synergism between B-type activity and PTB were both observed. A similar lack of response of the poliovirus IRES in XLPV1-747 was observed when recombinant unr was tested (see Fig. 6B).

Somewhat different results were seen when the template was either full-length poliovirus virion RNA or a transcript of the full-length poliovirus cDNA linearized near the end of the $\mathrm{P} 1$ coding region (pT7-1/NdeI). When fraction 26 from the affinity column (Fig. 1) was added to assays of virion RNA translation in reticulocyte lysate, it decreased the yield of some of the aberrant products initiated in the P3 region (Dorner et al. 1984) and gave a modest increase (3.5-fold) in the yield of unprocessed P1 (Fig. 5B). Because addition of fraction 26 caused no significant change in the yield of $\mathrm{P} 1$ processing products (VP0, VP1, and VP3), the increase in the yield of P1 must be the result of increased translation efficiency, and not simply the consequence of decreased processing of P1. In fact if the combined yield of unprocessed capsid precursor (P1) and its processed products (VP0, VP1, and VP3) was determined, fraction 26 was found to stimulate translation initiation by a factor of about twofold.

With the truncated transcript coding for P1 (T7-1) NdeI), partially purified B-type activity stimulated translation (by $80 \%$ over the buffer control), but to a lesser extent than recombinant PTB (which gave a $>200 \%$ increase); when both were added, the B-type activity augmented the PTB-dependent stimulation by only a small margin that we do not consider to be significant (Fig. 5C). In assays of recombinant unr with the same template, unr has never increased the efficiency of translation when added on its own, but it has occasionally augmented the stimulation effected by PTB, although this pairwise effect is rather fragile in that it seems dependent on precise conditions such as RNA and $\mathrm{K}^{+}$concentrations (data not shown).

It has been reported recently that poly(C)-binding protein 2 (PCBP-2) is necessary for internal initiation of translation dependent on the poliovirus IRES (Blyn et al. 1996, 1997), and Gamarnik and Andino (1997) have suggested that the closely related PCBP-1 has the same effect. Although we have shown previously that rabbit reticulocyte lysates contain sufficient PCBP not to be limiting for poliovirus IRES activity under normal circumstances (Hunt and Jackson 1999), we considered it important to eliminate the possibility that our failure to find a synergy between B-type activity (or recombinant unr) and PTB on poliovirus IRES activity might be due to insufficient PCBP-2. Accordingly, we tested the effect of various permutations of recombinant $\mathrm{PTB}$, recombinant unr, and recombinant PCBP-2 (and also recombinant p38 in some experiments) on the translation of the dicistronic mRNAs with the poliovirus and rhinovirus IRESes (Fig. 6). In the case of the HRV IRES, no stimulation was seen with PCBP-2 on its own, a slight stimulation by unr, and a stronger enhancement by PTB on its own; and in pairwise combinations, unr and PTB showed the usual strong synergy, addition of PCBP-2 augmented the stimulatory effect of PTB to a lesser extent, but PCBP-2 did not increase the stimulation promoted by unr (Fig. 6A). However, when all three of these recombinant proteins were added together, their effect in combination was significantly greater than that of PTB plus unr. 


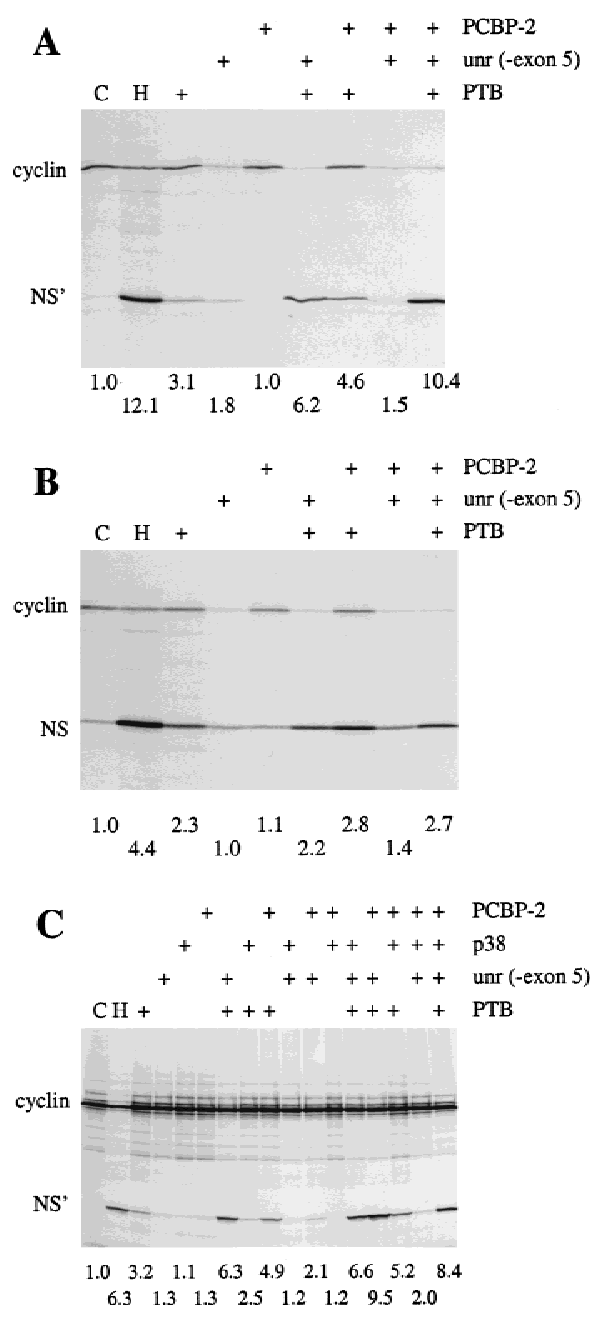

Figure 6. Comparison of the response of the HRV and poliovirus IRES elements to recombinant unr, PTB, and PCBP-2. Translation assays were carried out with either $(A)$ uncapped XLJHRV10-611, (B) uncapped XLPV1-746, or $(C)$ capped XLJHRV10-611 dicistronic mRNAs in reticulocyte lysate supplemented with $5 \mu \mathrm{g} / \mathrm{ml}$ His-unr (-exon 5), $10 \mu \mathrm{g} / \mathrm{ml} \mathrm{His-}$ PTB, $20 \mu \mathrm{g} / \mathrm{ml}$ His-PCPB-2, and $20 \mu \mathrm{g} / \mathrm{ml}$ recombinant Hisp38; each separately, or in various combinations as indicated above each lane. Control reactions were carried out either without the addition of factors (C) or supplemented with $20 \%$ (vol/ vol) HeLa cell HS S100 extract (H). An autoradiograph of the translation products, analyzed by SDS $/ 20 \%$ polyacrylamide gel electrophoresis, is shown. The yield of radiolabeled NS' in $A$ and $C$, or NS in $B$, was determined by quantitative densitometry and is given below each lane, expressed relative to the yield in the buffer control assay, which was assigned a value of 1.0.

A repetition of this experiment with capped XLJHRV 10-611 mRNA and with recombinant p38 also included in the test gave essentially the same results for stimulation of IRES-dependent translation by various permutations of the recombinant proteins (Fig. 6C). However, in this case, unr had only a marginal effect on the yield of upstream cistron translation product (cyclin), and given that the capping procedure is not $100 \%$ efficient (Dasso and Jackson 1989), we conclude that unr does not inhibit translation of capped mRNAs. Significantly, the influence of unr (acting in concert with PTB) on IRES-dependent cistron translation was no less with the capped transcript (Fig. 6C) than the uncapped form (Fig. 6A). This proves that unr acts directly to enhance the efficiency of internal initiation and that this stimulation is not a secondary consequence of inhibition of competing translation of the cyclin cistron. Figure 6C also confirms that recombinant p38 had no significant influence under any circumstances.

The results with the poliovirus IRES were similar for the single addition assays: Only PTB showed any significant stimulation (Fig. 6B). However, in the pairwise combinations with PTB, unr did not increase the yield of downstream cistron product seen with PTB alone, whereas PCBP-2 did to a small extent. The three-way combination was no better than the PTB-PCBP-2 pairing. Thus there is a clear difference between the two types of IRES with respect to which pairwise combination of factors is the best in promoting internal initiation: PTB plus PCBP-2 for the poliovirus IRES, as opposed to PTB plus unr for rhinovirus.

The lack of a clear response of the poliovirus IRES to recombinant unr was surprising, as we had noted previously that unr bound and could be cross-linked by UV irradiation to the poliovirus IRES. To examine this binding more quantitatively, we did competitive UV crosslinking assays using a ${ }^{32}$ P-labeled HRV 5' UTR probe, varying concentrations of unlabeled competitor HRV or poliovirus 5' UTR RNAs, and HeLa cell HS S100 extract (rather than recombinant unr in view of uncertainties as to whether the recombinant protein is in exactly the same native state as endogenous HeLa cell p97). The results of the competition assay implied that the affinity of unr for the poliovirus IRES was 10-fold lower than for the HRV IRES (S.L. Hunt and R.J. Jackson, unpubl.). On the other hand, the affinity of endogenous HeLa cell PTB for the poliovirus IRES was about 2-fold greater than for the HRV IRES.

\section{p38 and unr form an RNA-independent complex}

In view of the fact that we observed no functional activity with recombinant p38 in any assay, we were concerned as to whether p38 might be completely irrelevant and whether the apparent copurification of unr and p38 might have been fortuitous. We examined this issue in two ways: by coimmunoprecipitation assays and by Western blotting across all the fractions from all the successive columns used in the purification of B-type activity (p97/unr) with antibodies raised against the recombinant proteins.

For the coimmunoprecipitation test, polyclonal antibodies against unr or p38 were covalently coupled to protein A-Sepharose, which was used to pull out the corresponding antigen from HeLa cell HS S100 extract. The bound proteins were then examined by gel electrophoresis and Western blotting with a mixture of the two antisera. The results show that anti-unr antibodies pull down both unr and p38 antigens, and the same is true of 
Hunt et al.

A

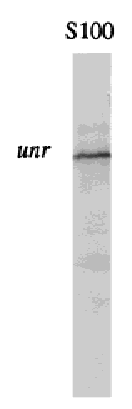

anti-unr
B

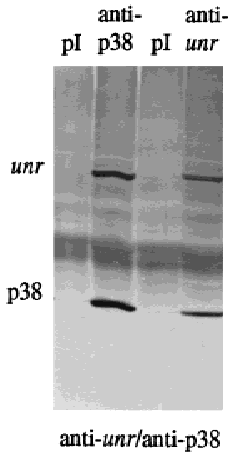

to state categorically whether all of the unr purified from HeLa cell extracts is associated with p38, but such an interpretation would be consistent with the intensity of Coomassie blue staining of fraction 27 of Figure 1A. Thus there is no doubt that p38 genuinely interacts with unr, and so we propose to name it unrip, for unr-interacting protein.

\section{Discussion}

The fact that poliovirus RNA is translated inefficiently in rabbit reticulocyte lysates unless HeLa cell cytoplasmic extract is added was first recognized many years ago (Brown and Ehrenfeld 1979; Dorner et al. 1984). Initial attempts to exploit this observation as a functional assay for the purification of the relevant factor(s) from HeLa, L, or Krebs II ascites cells met with little success (Svitkin et al. 1988; Jackson 1989). What we have reported here is the first successful attempt at achieving purification and identification of the stimulatory activities using a functional translation assay. Three factors were instrumental in this success: (1) use of a dicistronic mRNA so that translation of the upstream cistron can serve as an internal control for nonspecific inhibition or stimulation of translation; (2) the switch from the poliovirus to the rhinovirus IRES, as the latter gives a much lower background of IRES-dependent translation in the unsupplemented reticulocyte lysate (Figs. 5A and 6); and (3) the use of an HRV 5' UTR RNA-affinity column for the last step in purification, without which it would probably have been impossible to identify the B-type activity (Fig. 1).

The purified HeLa cell B-type activity was found to consist of unr associated with p38 (or unrip). Although we have produced convincing evidence that unr and p38 are associated in HeLa cells, strictly speaking we have not proven that p38 is an integral component of the stimulatory activity, as we observed no activity with recombinant p38. It is unlikely that this failure is due to the presence of sufficient singular p38 in reticulocyte lysates, as Western blotting of lysates gave only an extremely weak signal. We believe that the more likely explanation lies in improper folding of the recombinant p38, as evidenced by the low solubility of the recombinant protein. It is known that many GH-WD repeat proteins do not fold properly in the absence of their interacting partners (García-Higuera et al. 1996). (Consequently, we attempted coexpression of p38 and unr in $E$. coli, but this did not overcome the problem.)

It does not seem implausible that the inactivity of recombinant $\mathrm{p} 38$ provides the basis of the explanation for why recombinant unr shows little stimulation of HRV IRES-dependent translation unless PTB has also been added to the assays, whereas the purified HeLa cell Btype activity has more self sufficiency, although its stimulatory effect is also at least additive with that of PTB. Nevertheless, the fact that recombinant unr is active in the functional translation assay, albeit in special circumstances, surely puts its identification as the protein responsible for the B-type activity beyond doubt. 
What is particularly encouraging is that activation of the HRV IRES was observed at concentrations that are realistically physiological. In assays supplemented with about $10 \mathrm{~nm}$ dicistronic mRNA, a significant increase in IRES-dependent translation is seen when as little as 1 $\mu \mathrm{g} / \mathrm{ml}(10 \mathrm{nM})$ recombinant unr is added, together with saturating recombinant PTB (Fig. 4A); maximal stimulation is achieved with $2.5-5 \mu \mathrm{g} / \mathrm{ml}(25-50 \mathrm{nM})$ recombinant unr in this assay. In the case of PTB, half-maximal stimulation is seen with as little as $1 \mu \mathrm{g} / \mathrm{ml}(\sim 20 \mathrm{~nm})$ recombinant protein, and maximal stimulation with 5 $\mu \mathrm{g} / \mathrm{ml}$ ( 100 nM) PTB (Hunt and Jackson 1999).

It is also encouraging that in assays supplemented with a combination of recombinant unr, PTB, and PCBP2, the activity of the HRV IRES approached (Fig. 6A), or even exceeded (Fig. 6C), that observed when the assay was supplemented with $20 \%$ (by volume) HeLa HS S100 extract, which we have shown previously to be close to a saturating amount of HeLa cell extract at the particular RNA concentration used in these assays (Hunt and Jackson 1999). Using quantitative immunoblotting, we have estimated that the concentration of unr in an assay supplemented with $20 \%$ HeLa cell HS S100 extract will be of the order of $1 \mu \mathrm{g} / \mathrm{ml}(10 \mathrm{~nm})$. The fact that we have been able to reproduce the stimulation achieved by nearsaturating amounts of HeLa cell extract by using recombinant proteins at concentrations not very different from those that would have been actually contributed by the HeLa cell extract itself supports the belief that unr and PTB are the only trans-acting factors that (1) are required for HRV IRES function and (2) are present in HeLa cells at much greater abundance than in reticulocytes.

Our purification procedures did not score PCBP-2 as a HeLa cell factor that stimulates HRV IRES function, because, as we have shown previously, the concentration of PCBP in reticulocyte lysates is normally not limiting (Hunt and Jackson 1999). Consistent with this, a stimulation by PCBP-2 was seen in the experiment shown in Figure 6 only when the system was supplemented with saturating amounts of the appropriate other RNA-binding proteins: unr and PTB for the HRV IRES, or just PTB for the poliovirus IRES.

It is intriguing that all these proteins have multiple RNA-binding domains: five cold-shock domains in the case of unr (Fig. 3); four degenerate RNA recognition motifs (RRMs) in the case of the PTB monomer, although PTB probably exists as a dimer (Pérez et al. 1997b); and three KH-domains in the PCBP-2 monomer, which likewise probably exists as a dimer (Gamarnik and Andino 1997). We have created five mutants of unr, in which a critical phenylalanine residue in the RNA-binding surface of each individual cold-shock domain has been changed to alanine, and we find that all five mutant proteins show very reduced activity in the assay shown in Figure 4, implying that all five domains are necessary to support HRV IRES activity (E.C. Brown, S.L. Hunt, and R.J. Jackson, unpubl.). Multiple RNA-binding domains raise the possibility that the protein may contact the IRES at several different widely dispersed points, which has been shown to be the case for the interaction of PTB with cardiovirus and aphthovirus IRESes (Kolupaeva et al. 1996). As we have argued previously, such multipoint binding may contribute to the attainment or stabilization of the appropriate RNA tertiary structure required for internal initiation (Kaminski and Jackson 1998).

In view of the close phylogenetic relationship between poliovirus and rhinoviruses, and the similarity of their IRES structures, we were surprised to find that the two IRESes respond differently to various permutations of these RNA-binding proteins. The fact that unr had so small an influence on poliovirus IRES function cannot be ascribed to inappropriate folding of the recombinant protein in the absence of active recombinant p38/unrip, as HeLa cell B-type activity also effected very little stimulation and then only with poliovirus virion RNA or mRNAs with the poliovirus P1 coding region, not the dicistronic mRNAs with heterologous reporters (Fig. 5). These findings were surprising in view of the results of previous attempts to purify factors from HeLa, Krebs II, or L cells that could stimulate poliovirus RNA translation when added to reticulocyte lysates (Svitkin et al. 1988; Jackson 1989). In these assays, which, it should be noted, used virion RNA or transcripts of the full-length cDNA rather than laboratory-generated dicistronic mRNAs with heterologous reporter cistrons, only a very limited purification of the activity was achieved, but it is notable that on ion-exchange chromatography the activity behaved rather like the B-type activity and quite unlike PTB or PCBP-2.

While the idea that the HRV and poliovirus IRESes could have different requirements for trans-acting factors, specifically for unr, may seem counterintuitive, nevertheless it is entirely consistent with the fact that the relative abundance of the three RNA-binding proteins in reticulocyte lysates is $\mathrm{PCBP}>\mathrm{PTB}>>\mathrm{unr}$, yet the activity of the poliovirus IRES in the unsupplemented reticulocyte lysate is much higher than that of the HRV IRES (Figs. 5 and 6). It is also consistent with the results of Gromeier et al. (1996), who generated a poliovirus construct in which the endogenous IRES was replaced by that of HRV-2: The chimeric virus replicated as efficiently as wild-type poliovirus in HeLa cells, yet was completely restricted in cells of neuronal origin which nevertheless supported efficient replication of wild-type poliovirus. Therefore, it is with some caution that we suggest that the trans-acting factor requirements for translation of poliovirus and rhinovirus RNAs may differ.

\section{Materials and methods}

Preparation of the HeLa cell extract and purification of B-type activity

The preparation of HeLa cell S10 and HS S100 extracts was as described previously (Hunt and Jackson 1999). The HS S100 extract, which is essentially the postribosomal supernatant plus the ribosomal salt wash, was used as starting material for the purification. All chromatography steps were carried out at $4^{\circ} \mathrm{C}$, with buffers containing $20 \mathrm{mM}$ HEPES-KOH $(\mathrm{pH} 7.5), 2 \mathrm{~mm}$ $\mathrm{DTT}$, and $\mathrm{KCl}$ at the stated concentration (i.e., $\mathrm{HO}$ contains no 
salt, $\mathrm{H} 100$ is $100 \mathrm{~mm}$ in $\mathrm{KCl}$, and $\mathrm{H} 1000$ is $1000 \mathrm{~mm}$ in $\mathrm{KCl}$ ). Between column runs, fractions were stored frozen at $-80^{\circ} \mathrm{C}$. The salt concentration of each column fraction was estimated by measurement of its conductivity. For use in translation or UV cross-linking assays, aliquots of each fraction were adjusted to equivalent salt concentrations by dilution with an appropriate volume of $\mathrm{H} 0$ or $\mathrm{H} 1000$ buffer.

Two 30-ml batches of HeLa HS S100 extract were each separately loaded, by use of an FPLC system (Pharmacia), at 0.5 $\mathrm{ml} / \mathrm{min}$ onto a $13-\mathrm{ml}$ heparin-Sepharose (Pharmacia) column that had been equilibrated with H100. After washing with five column volumes of $\mathrm{H} 100$, elution was carried out with a $35-\mathrm{ml}$ linear $100-550 \mathrm{~mm} \mathrm{KCl}$ gradient, at a flow rate of $0.2 \mathrm{ml} / \mathrm{min}$. The B-type activity-enriched fractions (the $260-330 \mathrm{mM} \mathrm{KCl}$ eluate) from both columns were pooled, dialyzed extensively against H100, and applied, under gravity, to a 5-ml DEAE-Sepharose (FastFlow; Pharmacia) column in H100. After washing with 5 column volumes of H100, the B-type activity was eluted with $6 \mathrm{ml}$ of H200. The active fractions were pooled and divided into two aliquots that were each applied under gravity to a freshly prepared HRV 5' UTR affinity column, prepared by coupling $500 \mu \mathrm{g}$ of HRV 5' UTR RNA to $0.5 \mathrm{ml}$ of cyanogen bromide-activated Sepharose 4B (Pharmacia) by use of the method described previously (Kaminski et al. 1995, 1998). The flowthrough was recycled once over the matrix, before the column was washed with $2 \mathrm{ml}$ of $\mathrm{H} 200$ and then eluted with 750 $\mu \mathrm{l}$ each of $\mathrm{H} 300, \mathrm{H} 400$, and $\mathrm{H} 500$ followed by $500 \mu \mathrm{l}$ each of H700, H800, and H1000. The flowthrough and eluate were collected in $250-\mu 1$ fractions. The B-type activity was found in the 500-700 mм KCl eluate.

\section{Peptide sequencing}

Purified p97 and p38 ( 50 pmole of each) were separated by SDS-PAGE and stained with Coomassie Blue. The p97 doublet and p38 band were excised from the gel and digested in situ with endopeptidase lys-C and alkylated trypsin, respectively. Peptides were recovered by sonication and applied directly to Aquapore AX-300 $(30 \times 2.1 \mathrm{~mm})$ and OD-300 $(150 \times 2.1 \mathrm{~mm})$ columns connected in series on a Hewlett-Packard 1090M HPLC system. The columns were developed with a linear acetonitrile gradient in $0.1 \%$ trifluoroacetic acid while monitoring peptide elution by diode array detection (200-600 nm). Fractions were collected and applied to an Applied Biosystems 477A pulsed liquid automated sequencer modified as described previously (Totty et al. 1992).

\section{cDNA library screening}

One p38 peptide (AATAAADFTAK) matched exactly an EST from the GenBank database (accession no. HS78912), and two others (EISGHTSGIK and SIAFHSAVSLDPIK) matched the sequence of a single EST (HSAAACCLW-which was found to be part of an overlapping set of ESTs comprising also HS68412, HS05512, HS76414, HS62737, and HS78912). With these EST sequences, two oligonucleotides were designed (upstream primer, 5'-GCCGCCATGCCAATGAGAC-3'; downstream primer, $5^{\prime}$-TACTTACTGCACTATGAAAAGC-3') to amplify a 646-bp fragment by PCR from a UniZAP XR HeLa cell cDNA library (Stratagene). The resulting PCR fragment was used to screen the library for full-length p38 cDNA clones, by use of standard protocols recommended by Stratagene. The published sequence of unr was used to design two oligonucleotides: the upstream primer 5'-ATGAGCTTTGATCCCAAAGCTTC-3', which includes the initiation codon; and the downstream primer 5'-CCCATTACGTTCGTAGCATAG-3', complemen- tary to exon 5. These amplified a 402-bp fragment from the HeLa cDNA library, which was used to screen the library for full-length cDNA clones of both unr isoforms. Positive plaques were recovered from the UniZAP XR vector into the Bluescript phagemid by use of the Exassist/SOLR system (Stratagene) and the respective cDNA inserts sequenced automatically with an Applied Biosystems sequencer at the DNA Sequencing Facility, Department of Biochemistry, University of Cambridge. The GenEMBL accession number for p38 is AJ010025.

\section{Overexpression of recombinant proteins in E. coli}

The open reading frame of each unr isoform was amplified by PCR from the cDNA phagemids with two primers: the upstream primer, 5'-GACTGCGCCATGGGCTTTGATCC-3', which flanks the initiation codon, but changes the second codon from AGC to GGC so as to create a unique NcoI restriction site (italicized); and the downstream primer, 5'-CCCCCAAGCTTGTCAATGACACCAGCTTGACGG-3', which is complementary to sequences immediately adjacent to the termination codon and contains a HindIII site (italicized). The PCR products were digested with NcoI and HindIII and cloned into pET21d vector (Novagen) that had also been digested with NcoI and HindIII, generating constructs for the overexpression of unr with a carboxy-terminal hexahistidine fusion in E. coli. The p38-coding sequence was also subcloned into pET21d, by digestion of pBSp38 with NcoI and StuI, and ligation of the excised fragment into pET21d, which had been digested with HindIII, filled in with Klenow, and then digested with NcoI. After verifying the sequence of the subcloned expression constructs, all three histidine-tagged fusion proteins were expressed in E. coli BL21(DE3)lysS cells and purified using Ni-NTA Sepharose (Qiagen), in accordance with the manufacturer's guidelines. pET28aPTB for overexpression of recombinant histidine-tagged human PTB-1 was provided by J.G. Patton (Pérez et al. 1997a). Histidine-tagged PTB was overexpressed in E. coli BL21(DE3) cells and then purified as for unr and p38 histidine-tagged proteins. pGEX3XPTB (Patton et al. 1991) was used for the overexpression of GST-PTB fusion protein, which was purified as described by Smith and Corcoran (1990). All purified recombinant proteins were extensively dialyzed against H100 buffer [20 mM HEPES-KOH (pH 7.5), $100 \mathrm{~mm} \mathrm{KCl,} 2 \mathrm{~mm}$ DTT] prior to supplementation into translation assays. Recombinant histidine-tagged PCBP-2 was purified according to Parsley et al. (1997).

\section{In vitro transcription and translation}

Uncapped RNA for in vitro translation assays was transcribed from the dicistronic plasmids pXLJHRV10-611 or pXLPV1-747, and from pHRV-2 or pT7-1 as described previously (Hunt and Jackson 1999). Capped RNAs were generated as described by Dasso and Jackson (1989). In both dicistronic plasmids the upstream cistron encodes $X$. laevis cyclin B2: pXLJHRV10-611 has the complete HRV-2 5' UTR (except for the first 9 nucleotides) linked directly to a slightly truncated form of the influenza virus NS1 cDNA (Borman and Jackson 1992; Borman et al. 1993); pXLPV1-747 has the complete 5' UTR of poliovirus type 1 (Mahoney) fused to the unadulterated NS1 open reading frame via a short linker. pHRV-2 and pT7-1 are full-length cDNA clones of rhinovirus- 2 and poliovirus type 1 , respectively, which were linearized with NdeI at nucleotide 3603 (pHRV-2) or 3381 (pT7-1), to generate mRNAs coding respectively for $\mathrm{P} 1,2 \mathrm{~A}$, and part of $2 \mathrm{~B}$, or a slightly truncated $\mathrm{P} 1$ capsid precursor (Hunt and Jackson 1999).

Translation assay conditions were as described previously (Hunt and Jackson 1999) unless otherwise stated. For the trans- 
lation of poliovirus virion $\mathrm{RNA}$, the $\mathrm{KCl}$ concentration was reduced to $65 \mathrm{~mm}$, and the reaction was incubated for $3 \mathrm{hr}$. For the assay of HeLa cell extract or column fractions, these additions were typically made at $20 \%$ (vol/vol), unless otherwise stated. All column fractions were adjusted to equivalent $\mathrm{KCl}$ concentrations to ensure consistent conditions for all assays. Translation products resolved by SDS-PAGE were visualized by autoradiography with Hyperfilm $\beta$ Max (Amersham). The autoradiographs were quantitated by densitometry with the Phoretix software package.

\section{Immunological methods}

Recombinant GST-unr(+exon5) and GST-p38 fusion proteins, overexpressed in E. coli (BL21 strain), were recovered from SDSpolyacrylamide gel slices by electroelution and used to immunize rabbits in accordance with standard procedures (Harlow and Lane 1988). Antibody production was carried out by Harlan SeraLabs (Loughborough, UK.).

For immunoprecipitations, antibodies were chemically coupled to protein A-Sepharose beads by the following procedure: $100 \mu \mathrm{l}$ of protein A-Sepharose (Pharmacia Biotech) was preincubated for $1 \mathrm{hr}$ at $4^{\circ} \mathrm{C}$ in an end-over-end rotator in $5 \mathrm{ml}$ of $5 \%$ BSA in NET buffer [50 mm Tris- $\mathrm{HCl}(\mathrm{pH} 7.5), 150 \mathrm{~mm}$ $\mathrm{NaCl}, 0.5 \%$ NP-40, 1 mM EDTA, $0.25 \%$ gelatin, $0.02 \%$ sodium azide], before the addition of $100 \mu \mathrm{l}$ of serum (or preimmune serum) and further incubation for $2 \mathrm{hr}$ under the same conditions. The matrix was then washed 3 times with $1 \mathrm{ml}$ of $5 \%$ BSA in NET buffer, two times with $1 \mathrm{ml}$ of coupling buffer 13 vols of $0.1 \mathrm{M}$ sodium tetraborate, 8 vols of $0.1 \mathrm{~m}$ boric acid at $\mathrm{pH}$ 9.0 ), and finally once with $1 \mathrm{ml}$ of $1 \%$ dimethyl pimelimidate dihydrochloride (Sigma) in $0.1 \mathrm{M}$ sodium tetraborate. Coupling was carried out by overnight incubation at $4^{\circ} \mathrm{C}$ with $1 \mathrm{ml}$ of $1 \%$ dimethyl pimelimidate dihydrochloride in $0.1 \mathrm{M}$ sodium tetraborate. The matrix was then incubated for $10 \mathrm{~min}$ at room temperature with $1 \mathrm{ml}$ of $1 \mathrm{M}$ Tris- $\mathrm{HCl}(\mathrm{pH} 9.0)$ and washed three times with $1 \mathrm{ml}$ of storage buffer $(7$ vols of $0.1 \mathrm{M}$ sodium tetraborate, 100 vols of $0.1 \mathrm{M}$ boric acid). For immunoprecipitation assays, $5 \mu \mathrm{l}$ of antibody-coupled protein A-Sepharose was first equilibrated with $5 \%$ BSA in H100 buffer, then incubated with $20 \mu \mathrm{l}$ of HeLa HS S100 extract in $500 \mu \mathrm{l}$ of $5 \%$ BSA in H100 in an end-over-end rotator at $4^{\circ} \mathrm{C}$ for $1 \mathrm{hr}$. The matrix was then washed five times with $1 \mathrm{ml}$ of $\mathrm{H} 100$ (not containing BSA), before the addition of $20 \mu \mathrm{l}$ of SDS gel loading buffer. Samples were boiled for $2 \mathrm{~min}$, then analyzed by SDS-PAGE and immunoblotting by use of procedures described in Hunt and Jackson (1999).

\section{Acknowledgments}

We thank John Lester and the DNA Sequencing Facility for automated DNA sequencing; C. Gooding for overexpression and purification of His-PTB; J. G. Patton for pET28aPTB; Bert L. Semler and Todd Parsley for a gift of recombinant PCBP-2 and poliovirus virion RNA; Hélène Jacquemin-Sablon and F. Dautry for communicating results prior to publication and for conducting preliminary Western blots; and Catherine L. Gibbs for technical assistance. This work was supported by grants from The Wellcome Trust and European Commission Biotechnology Program (BIO4-CT95-0045). S.L.H was supported by a research studentship from the Medical Research Council, and also by grants from the Wellcome Trust.

The publication costs of this article were defrayed in part by payment of page charges. This article must therefore be hereby marked 'advertisement' in accordance with 18 USC section 1734 solely to indicate this fact.

\section{References}

Bailly, J-L., A.M. Borman, H. Peiguelafeuille, and K.M. Kean. 1996. Natural isolates of echo virus type- 25 with extensive variations in IRES sequences and different translational efficiencies. Virology 21: 83-96.

Blyn, L.B., K.M. Swiderek, O. Richards, D.C. Stahl, B.L. Semler, and E. Ehrenfeld. 1996. Poly $(\mathrm{rC})$ binding protein 2 binds to stem-loop IV of the poliovirus RNA 5' noncoding region: Identification by automated liquid chromatography-tandem mass spectrometry. Proc. Nat1. Acad. Sci. 93: 11115-11120.

Blyn, L.B., J.S. Towner, B.L. Semler, and E. Ehrenfeld. 1997. Requirement of poly $(\mathrm{rC})$ binding protein 2 for translation of poliovirus RNA. J. Virol. 71: 6243-6246.

Borman, A.M. and R.J. Jackson. 1992. Initiation of translation of human rhinovirus RNA: Mapping the internal ribosome entry site. Virology 188: 685-696.

Borman, A.M., M.T. Howell, J.G. Patton, and R.J. Jackson. 1993. The involvement of a spliceosome component in internal initiation of human rhinovirus RNA translation. J. Gen. Virol. 74: $1775-1788$.

Borman, A.M., J.-L. Bailly, M. Girard, and K.M. Kean. 1995. Picornavirus internal ribosome entry segments-comparison of translation efficiency and the requirements for optimal internal initiation of translation in vitro. Nucleic Acids Res. 23: 3656-3663.

Borman, A.M., R. Kirchweger, E. Ziegler, R.E. Rhoads, T. Skern, and K.M. Kean. 1997. eIF4G and its proteolytic cleavage products: Effect on initiation of protein synthesis from capped, uncapped and IRES-containing mRNAs. RNA 3: 186-196.

Boussadia, O., H. Jacquemin-Sablon, and F. Dautry. 1993. Exon skipping in the expression of the gene immediately upstream of N-ras (unr/NRU). Biochim. Biophys. Acta 1172: 64-72.

Boussadia, O., F. Amiot, S. Cases, G. Triqueneaux, H. Jacquemin-Sablon, and F. Dautry. 1997. Transcription of unr (uppstream of $\underline{N}$-ras) down-modulates $\mathrm{N}$-ras expression in vivo. FEBS Lett. 420: 20-24.

Brown, B. and E. Ehrenfeld. 1979. Translation of poliovirus RNA in vitro: Changes in cleavage pattern and initiation sites by ribosomal salt wash. Virology 97: 396-405.

Dasso, M.C. and R.J. Jackson. 1989. Efficient initiation of mammalian mRNA translation at a CUG codon. Nucleic Acids Res. 17: 6485-6497.

Doniger, J., D. Landsman, M.A. Gonda, and G. Wistow. 1992. The product of unr, a highly conserved gene upstream of $\mathrm{N}$-ras, contains multiple repeats similar to the cold-shock domain (CSD), a putative DNA-binding motif. New Biologist 4: 389-395.

Dorner, A.J., B.L. Semler, R.J. Jackson, R. Hanecak, E. Duprey, and E. Wimmer. 1984. In vitro translation of poliovirus RNA: Utilization of internal initiation sites in reticulocyte lysate. J. Virol. 50: 507-514.

Gamarnik, A.V. and R. Andino. 1997. Two functional complexes formed by $\mathrm{KH}$ domain containing proteins with the $5^{\prime}$ noncoding region of poliovirus RNA. RNA 3: 882-892.

García-Higuera, I., J. Fenoglio, Y. Li, C. Lewis, M.P. Panchenko, O. Reiner, T.F. Smith, and E.J. Neer. 1996. Folding of proteins with WD-repeats-comparison of 6 members of the WD-repeat superfamily to the G-protein $\beta$-subunit. Biochemistry 35: 13985-13994.

Graumann, P.L. and M.A. Marahiel. 1998. A superfamily of proteins that contain the cold-shock domain. Trends Biochem. Sci. 23: 286-290.

Gromeier, M., L. Alexander, and E. Wimmer. 1996. Internal ribosome entry site substitution eliminates neurovirulence 
in intergenic poliovirus recombinants. Proc. Natl. Acad. Sci. 93: $2370-2375$.

Harlow, E. and D.P. Lane. 1988. Antibodies: A laboratory manual. Cold Spring Harbor Laboratory, Cold Spring Harbor, New York, NY.

Hunt, S.L. and R.J. Jackson. 1999. Polypyrimidine tract binding protein $(\mathrm{PTB})$ is necessary, but not sufficient, for efficient internal initiation of translation of human rhinovirus-2 RNA. RNA (in press).

Jackson, R.J. 1989. Comparison of encephalomyocarditis virus and poliovirus with respect to translation initiation and processing in vitro. In Molecular aspects of picornavirus infection and detection (ed. B.L. Semler and E. Ehrenfeld), pp 51-71. American Society for Microbiology, Washington, DC.

Jackson, R.J. and A. Kaminski. 1995. Internal initiation of translation in eukaryotes: The picornavirus paradigm and beyond. RNA 1: 985-1000.

Jacquemin-Sablon, H., G. Triqueneaux, S. Deschamps, M. le Maire, J. Doniger, and F. Dautry. 1994. Nucleic acid binding and intracellular localization of unr, a protein with five cold shock domains. Nucleic Acids Res. 22: 2643-2650.

Jang, S.K., H-G. Krausslich, M.J.H. Nicklin, G.M. Duke, A.C. Palmenberg, and E. Wimmer. 1988. A segment of the $5^{\prime}$ nontranslated region of encephalomyocarditis virus RNA directs internal entry of ribosomes during in vitro translation. $J$. Virol. 62: 2636-2643.

Jeffers, M., R. Paciucci, and A. Pellicer. 1990. Characterization of unr: A gene closely linked to N-ras. Nucleic Acids Res. 18: $4891-4899$.

Kaminski, A. and R.J. Jackson. 1998. The polypyrimidine tract binding protein (PTB) requirement for internal initiation of translation of cardiovirus RNAs is conditional rather than absolute. RNA 4: 626-638.

Kaminski, A., S.L. Hunt, J.G. Patton, and R.J. Jackson. 1995. Direct evidence that polypyrimidine tract binding protein (PTB) is essential for internal initiation of encephalomyocarditis virus RNA translation. RNA 1: 924-938.

Kaminski, A., D.H. Ostareck, N.M. Standart, and R.J. Jackson. 1998. Affinity methods for isolating RNA binding proteins. In RNA: protein interactions: A practical approach (ed. C.W.J. Smith), pp 137-160. Oxford University Press, Oxford, UK.

Kolupaeva, V.G., C.U.T. Hellen, and I.N. Shatsky. 1996. Structural analysis of the interaction of the pyrimidine tract binding protein with the internal ribosome entry segment of encephalomyocarditis virus and foot-and-mouth disease virus. RNA 2: 1199-1212.

Lin, C.H. and J.G. Patton. 1995. Regulation of alternative 3' splice site selection by constitutive splicing factors. RNA 1: $234-245$.

Naranda, T., M. Kainuma, S.E. MacMillan, and J.W.B. Hershey. 1997. The 39-kilodalton subunit of eukaryotic translation initiation factor 3 is essential for the complex's integrity and for cell viability in Saccharomyces cerevisiae. Mol. Cell. Biol. 17: 145-153.

Nicolaiew, N., G. Triqueneaux, and F. Dautry. 1991. Organization of the human $N$-ras locus: Characterization of a gene found immediately upstream of $N$-ras. Oncogene 6: 721 730.

Ohlmann, T., M. Rau, V.M. Pain, and S.J. Morley. 1997. The C-terminal domain of eukaryotic protein synthesis initiation factor eIF4G is sufficient to support cap-independent translation in the absence of eIF4E. EMBO J. 15: 1371-1382.

Parsley, T.B., J.S. Towner, L.B. Blyn, E. Ehrenfeld, and B.L. Semler. 1997. Poly $(\mathrm{rC})$ binding protein 2 forms a ternary complex with the $5^{\prime}$-terminal sequences of poliovirus RNA and the viral 3CD proteinase. RNA 3: 1124-1134.

Patton, J.G., S.A. Mayer, P. Tempst, and B. Nadal-Ginard. 1991. Characterization and molecular cloning of polypyrimidine tract binding protein: A component of a complex necessary for pre-mRNA splicing. Genes \& Dev. 5: 1237-1251.

Pelletier, J. and N. Sonenberg. 1988. Internal initiation of translation of eukaryotic mRNA directed by a sequence derived from poliovirus RNA. Nature 334: 320-325.

Pérez, I., C.-H. Lin, J.G. McAfee, and J.G. Patton. 1997a. Mutation of PTB binding sites causes misregulation of alternative $3^{\prime}$ splice site selection in vivo. RNA 3: 764-778.

Pérez, I., J.G. McAfee, and J.G. Patton. 1997b. Multiple RRMs contribute to RNA binding specificity and affinity for polypyrimidine tract binding protein. Biochemistry 36: 1188111890.

Pestova, T.V., C.U.T. Hellen, and I.N. Shatsky. 1996a. Canonical eukaryotic initiation-factors determine initiation of translation by internal ribosomal entry. Mol. Cell. Biol. 16: 6859-6869.

Pestova, T.V., I.N. Shatsky, and C.U.T. Hellen. 1996b. Functional dissection of eukaryotic initiation-factor $4 \mathrm{~F}-$ the $4 \mathrm{~A}$ subunit and the central domain of the 4G subunit are sufficient to mediate internal entry of $43 \mathrm{~S}$ preinitiation complexes. Mol. Cell. Biol. 16: 6870-6878.

Schindelin, H., M.A. Marahiel, and U. Heinemann. 1993. Universal nucleic acid-binding domain revealed by crystal structure of the B. subtilis major cold shock protein. Nature 364: 164-168.

Schnuchel, A., R. Wiltschek, M. Czisch, M. Herrier, G. Willimsky, P. Graumann, M.A. Marahiel, and T.A. Holak. 1993. Structure in solution of the major cold shock protein from Bacillus subtilis. Nature 364: 169-171.

Schröder, K., P. Graumann, A. Schnuchel, T.A. Holak, and M.A. Marahiel. 1995. Mutational analysis of the putative nucleic acid-binding surface of the cold-shock domain, CspB, revealed an essential role of aromatic and basic residues in binding of single-stranded DNA containing the Y-box motif. Mol. Microbiol. 16: 699-708.

Sondek, J., A. Bohm, D.G. Lambright, H.E. Hamm, and P.B. Sigler. 1996. Crystal structure of $\mathrm{a}_{\mathrm{A}}$ protein $\beta \gamma$ dimer at 2.1 Å resolution. Nature 379: 369-374.

Smith, D.B. and L.M. Corcoran. 1990. Expression and purification of glutathione-S-transferase fusion proteins. In Current protocols in molecular biology (ed. F.M. Ausubel, R. Brent, R.E. Kingston, D.D. Moore, J.G. Seidman, J.A. Smith, and K. Struhl), pp. 16.7.1-16.7.8. John Wiley and Sons, New York, NY.

Svitkin, Y.V., T.V. Pestova, S.V. Maslova, and V.I. Agol. 1988. Point mutations modify the response of poliovirus RNA to a translation initiation factor: A comparison of neurovirulent and attenuated strains. Virology 166: 394-404.

Totty, N.F., M.D. Waterfield, and J.J. Hsuan. 1992. Accelerated high-sensitivity microsequencing of proteins and peptides using a miniature reaction cartridge. Protein Science 1: 1215-1224. 


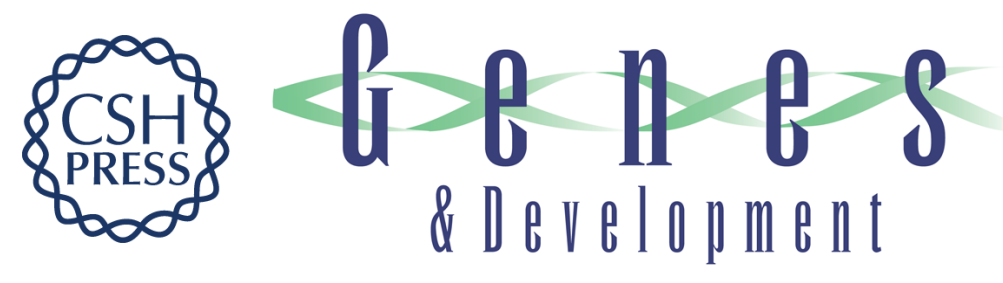

\section{unr, a cellular cytoplasmic RNA-binding protein with five cold-shock domains, is required for internal initiation of translation of human rhinovirus RNA}

Sarah L. Hunt, Justin J. Hsuan, Nicholas Totty, et al.

Genes Dev. 1999, 13:

References This article cites 39 articles, 17 of which can be accessed free at: http://genesdev.cshlp.org/content/13/4/437.full.html\#ref-list-1

License

Email Alerting Receive free email alerts when new articles cite this article - sign up in the box at the top Service right corner of the article or click here.

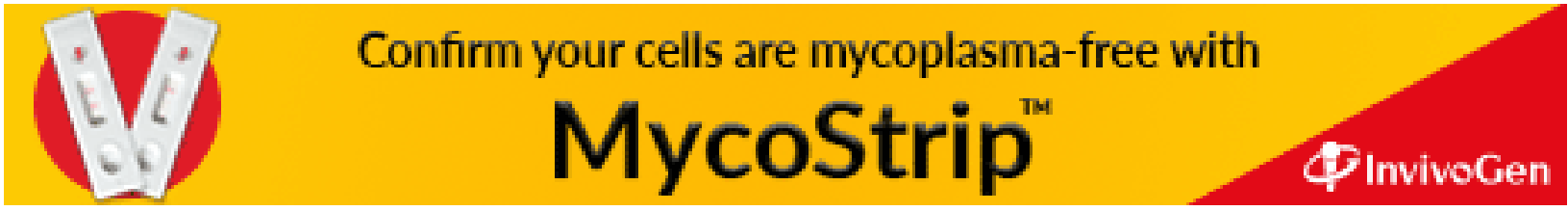

